\title{
KAJIAN NUMERIK MASALAH SYARAT BATAS MELALUI PENYELESAIAN MATRIKS TRIDIAGONAL (Studi Kasus : Menghitung Potensial Listrik)
}

\author{
Tatik Juwariyah \\ Fakultas Teknik,UPN "Veteran” Jakarta \\ Kampus Jalan RS. Fatmawati Pondok Labu Jakarta 12450, Indonesia, \\ email : tatikjuwariyah@gmail.com
}

\begin{abstract}
A numerical study of the solution of boundary value problems with the tridiagonal matrix approach has been done. The case studied is computing the electrical potential expressed by $1 D$ Poisson's equation with boundary conditions. The $1 D$ Poisson's equations are then discreted with the finite different method so as to form a system of linier equations. The system of non-homogeneous linear equations that can be formed is a tridiagonal matrix. Then the matrix is solved by Gaussian elimination algorithm. On this study, the algorithm is implemented on three programming languages namely, Fortran, Java and MATLAB.

Keywords: Gaussian elimination, finite different, tridiagonal matrix, Poisson's equation
\end{abstract}

\section{PENDAHULUAN}

Masalah syarat batas (boundary-value problems) sering muncul pada persamaan diferensial baik persamaan diferensial biasa ataupun persamaan diferensial parsial yang merupakan pondasi kajian ilmu-ilmu fisika terapan. Beberapa kasus masalah syarat batas dijumpai pada perhitungan potensial kelistrikan, potensial gravitasi, gelombang elektromagnetika, aliran fluida dan aliran panas. Terdapat dua cara yang dapat ditempuh untuk menyelesaikan masalah syarat batas pada sebuah persamaan diferensial yaitu secara analitik dan secara numerik. Cara numerik lebih dipilih oleh para insinyur dikarenakan lebih efisien dalam menyelesaikan masalah di lapangan yang biasanya lebih kompleks dan rumit. Sementara cara analitik ditempuh jika syarat batasnya ideal dan sederhana dikarenakan penyelesaian secara analitik membutuhkan piranti matematika lanjutan seperti deret Fourier, transformasi Laplace ataupun fungsi-fungsi khas (fungsi Gamma, fungsi Beta, fungsi Green, fungsi Bessel, fungsi Legendre, dsb).

Perkembangan komputer sebagai alat hitung yang handal sangat membantu penyelesaian masalah-masalah di bidang keteknikan. Berbagai piranti lunak yang telah aplikatif dan berbentuk GUI (grafic user interface) semakin mempermudah dalam mensimulasikan masalah-masalah nyata.
Meskipun telah banyak piranti lunak siap pakai yang lebih aplikatif untuk menyelesaikan kasuskasus yang melibatkan persamaan diferensial memilih bahasa pemrograman terstruktur (seperti Fortran, Basic, Pascal, C/C++ dan Java) untuk menyelesaikan masalah langkah demi langkah merupakan salah satu cara yang baik digunakan oleh akademisi pendidikan. Hal ini dikarenakan melatih dan mengasah ketrampilan proses pendidikan/pengajaran.

\section{TINJAUAN PUSTAKA \\ Potensial Elektrostatik}

Medan listrik yang menembus suatu permukaan khayal dapat dijelaskan oleh hukum Gauss dalam bentuk diferensial dinyatakan sebagai :

$$
\nabla \bullet E=\rho / \varepsilon_{0}
$$

Medan listrik $\mathbf{E}$ adalah gradien potensial istrik $\phi$ dinyatakan oleh ungkapan :

$$
E=-\nabla \phi
$$

Substitusi persamaan (2) ke persamaan (1) diperoleh:

$$
\nabla \bullet \nabla \phi=-\rho / \varepsilon_{0}
$$

Dikarenakan operator nabla $\nabla$ adalah vektor maka dapat disederhanakan sehingga berbentuk

$$
\nabla^{2} \phi=-\rho / \varepsilon_{0}
$$

Bentuk matematis persamaan (3) dikenal dengan Persamaan Poisson. Jika ruas kanan persamaan Poisson bernilai nol persamaan akan 
mereduksi menjadi persamaan Laplace seperti berikut,

$$
\nabla^{2} \phi=0
$$

Persamaan Laplace dapat ditemukan di banyak fenomena seperti aliran fluida, elektrostatika, gelombang elektromagnetika dan aliran panas. berikut,

Persamaan Poisson 1D ditulis sebagai

$$
\frac{d^{2} \phi}{d x^{2}}=-\rho / \varepsilon_{0}
$$

Bentuk umum persamaan Poisson 1D secara matematis tidak lain adalah persaman diferensial berbentuk :

$$
\frac{d^{2} y(x)}{d x^{2}}=f(x)
$$

Penyelesaian/solusi khusus persamaan (6) dapat diperoleh jika kondisi batas $\mathrm{y}(\mathrm{x})$ diketahui.

\section{Diskritisasi Persamaan Diferensial}

Diskritisasi dengan metode beda hingga yaitu beda pusat (central difference) suku ruas kiri persamaan (6) berubah menjadi :

$$
\frac{d^{2} y\left(x_{i}\right)}{d x^{2}}=\frac{y_{i-1}-2 y_{i}+y_{i+1}}{(\Delta x)^{2}}+O(\Delta x)^{2}
$$

Dengan $\mathrm{O}(\Delta \mathrm{x})^{2}$ adalah kesalahan perhitungan numerik. Apabila syarat/kondisi batas $\mathrm{y}(\mathrm{x})$ diketahui maka dengan metode beda hingga dengan mengambil sejumlah $\mathrm{N}$ titik-titik grid, penyelesaian yang diinginkan adalah $\mathrm{y}(\mathrm{x})$ pada ranah $\mathrm{x}_{0} \leq \mathrm{x} \leq \mathrm{x}_{\mathrm{N}}$ dimana nilai atau bentuk penyelesaian pada kedua titik batas yaitu $\mathrm{y}\left(\mathrm{x}_{0}\right)=$ $\mathrm{y}_{0}$ dan $\mathrm{y}\left(\mathrm{x}_{\mathrm{N}}\right)=\mathrm{y}_{\mathrm{N}}$ sudah diketahui. Dengan metode beda hingga persamaan (6) akan berubah menjadi

$$
y_{i-1}-y_{i}+y_{i+1}=h^{2} f_{i}
$$

Dengan $\mathrm{h}=\Delta \mathrm{x}$ adalah lebar langkah perhitungan numerik.

Berbeda dengan masalah syarat awal, disini nilai $\mathrm{y}(\mathrm{x})$ yang akan dicari harus sesuai pada batas $\mathrm{x}_{0}$ dan $\mathrm{x}_{\mathrm{N}}$. Ini berarti persamaan (8) tidak dapat diselesaikan satu persatu untuk tiap i tertentu tetapi harus diselesaikan secara serentak untuk seluruh i yang ada. Artinya apabila nilai N besar maka cacah persamaan menjadi banyak sekali. Salah satu metode paling efektif untuk memecahkan banyak persamaan secara serentak adalah menggunakan cara sistem persamaan linier/matriks.
Persamaan

(8) berubah menjadi sistem persamaan linier(matriks) yang unik karena hanya berisi tiga koefisien di setiap barisnya sehingga matriks koefisien yang unik ini dikenal dengan matriks tridiagonal.

$$
\left(\begin{array}{cccccc}
-2 & 1 & 0 & \ldots & 0 & 0 \\
1 & -2 & 1 & & 0 \\
0 & 1 & -2 & 1 & \\
\vdots & & & \ddots & & \\
0 & & & 1 & -2 & 1 \\
0 & 0 & \ldots & 0 & 1 & -2
\end{array}\right)\left(\begin{array}{c}
y_{1} \\
y_{2} \\
\cdot \\
\cdot \\
y_{N-2} \\
y_{N-1}
\end{array}\right)=\left(\begin{array}{c}
h^{2} f_{1}-y_{0} \\
h^{2} f_{2} \\
\cdot \\
\cdot \\
h^{2} f_{N-2} \\
h^{2} f_{N-1}-y_{N}
\end{array}\right)
$$

Salah satu metode efisien untuk menyelesaikan sistem persamaan simultan yang tersusun atas matriks tridiagonal adalah dengan eleminasi Gauss yaitu dengan mengeliminasi unsur-unsur yang terletak persis di bawah diagonal utama. Bentuk umum persamaan (9) seperti berikut:

$$
\left(\begin{array}{ccccccc}
b_{1} & c_{1} & & 0 & \ldots & 0 & 0 \\
a_{2} & b_{2} & & c_{2} & & 0 \\
0 & & b_{3} & & & \\
\vdots & & & \ddots & & \\
0 & & & a_{N-2} & b_{N-2} & c_{N-2} \\
0 & 0 & \ldots & 0 & a_{N-1} & b_{N-1}
\end{array}\right)\left(\begin{array}{c}
y_{1} \\
y_{2} \\
\cdot \\
y_{N-2} \\
y_{N-1}
\end{array}\right)=\left(\begin{array}{c}
r_{1} \\
r_{2} \\
\cdot \\
\cdot \\
r_{N-2} \\
r_{N-1}
\end{array}\right)
$$

Dengan mendefinisikan kaitan

$\beta_{j}=b_{j}-\frac{a_{j}}{\beta_{j-1}} c_{j-1} \quad \rho_{j}=r_{j}-\frac{a_{j}}{\beta_{j-1}} \rho_{j-1}$ untuk $j=2,3, \ldots, \mathrm{N}-1$ dimana $\beta_{1}=b_{1}$ dan $\rho_{1}=r_{1}$ maka persamaan (10) berubah menjadi bentuk persamaan matriks berikut

$$
\left(\begin{array}{ccccccc}
\beta_{1} & c_{1} & & 0 & \ldots & 0 & 0 \\
0 & \beta_{2} & & c_{2} & & 0 \\
0 & & \beta_{3} & & & \\
\vdots & & & \ddots & & \\
0 & & & 0 & \beta_{N-2} & c_{N-2} \\
0 & 0 & \ldots & 0 & 0 & \beta_{N-1}
\end{array}\right)\left(\begin{array}{c}
y_{1} \\
y_{2} \\
\cdot \\
\cdot \\
y_{N-2} \\
y_{N-1}
\end{array}\right)=\left(\begin{array}{c}
\rho_{1} \\
\rho_{2} \\
\cdot \\
\cdot \\
\rho_{N-2} \\
\rho_{N-1}
\end{array}\right)
$$

Bentuk persamaan (11) sangat menarik karena memungkinkan semua $\mathrm{y}_{\mathrm{i}}$ dapat diperoleh dengan cara substitusi balik yaitu pertama dihitung $\mathrm{y}_{\mathrm{N}-1}$ melalui kaitan 


$$
y_{N-1}=\frac{\rho_{N-1}}{\beta_{N-1}}
$$

Setelah $\mathrm{y}_{\mathrm{N}-1}$ didapatkan maka $\mathrm{y}_{\mathrm{i}}$ yang lain diperoleh melalui kaitan untuk $\mathrm{j}=2,3, \ldots, \mathrm{N}-1$ sebagai berikut

$$
y_{N-j}=\frac{\rho_{N-1}-c_{N-j} y_{N-j+1}}{\beta_{N-j}}
$$

\section{METODE PENELITIAN}

Langkah-langkah penyelesaian kasus masalah di penelitian ini dijabarkan sebagai berikut.

\section{Pemodelan Matematis Masalah}

Penyelesaian masalah menghitung potensial listrik satu dimensi yang menjadi kasus masalah pada penelitian ini adalah andaikan ditinjau suatu daerah antara $0 \leq \mathrm{x} \leq 3$ yang memiliki rapat muatan berbentuk $\rho(x)=3 \varepsilon_{0} x$ dan adanya syarat batas nilai potensial $\phi(0)=10$ dan $\phi(3)=0$. Masalah ini dapat dirumuskan seperti persamaan (6) dengan mengambil $\mathrm{y}(\mathrm{x})=$ $\phi \quad(\mathrm{x})$ dan $f(x)=\rho(x) / \varepsilon_{0}=3 \varepsilon_{0} x / \varepsilon_{0}=-3 x$. Sehingga diperoleh model matematis masalah yaitu PD berbentuk :

$$
\frac{d^{2} \phi}{d x^{2}}=-3 x
$$

Dengan syarat batas diketahui $\phi(0)=10$ dan $\phi(3)$ $=0$.

\section{Algoritma Penyelesaian Numerik}

\section{Input :}

a. Banyaknya N (cacah perhitungan dalam hal ini terkait dengan ukuran matriks persegi).

b. Daerah selang x yang ditinjau.

c. Lebar langkah perhitungan

d. Syarat batas $y(0)$ dan $y(N)$.

2. Mengisi unsur-unsur matrik tridiagonal dan vektor kolom ruas kanan a(i), b(i), c(i) dan $r(i)$. Khusus untuk $\mathrm{i}=1$ dan $\mathrm{i}=\mathrm{N}-1$, unsur matriks $r(i)$ berbeda dengan yang lain karena ada pengurangan dengan $\mathrm{y}_{0}$ dan $\mathrm{y}_{\mathrm{n}}$.

3. Algoritma Eliminasi Gauss : mengubah matriks tridiagonal ke bentuk matriks atas yang hanya mengandung dua larik yaitu beta(i) dan c(i) serta r(i) ke rho(i).

Menghitung y(i) dengan substitusi balik yaitu dihitung lebih dahulu $\mathrm{y}(\mathrm{n}-1)$ dan dilanjutkan ke y(n-2) dan seterusnya sampai $\mathrm{y}(1)$.

4. Menampilkan hasil.
5. Membuat subprogram/subroutine untuk mendefinisikan fungsi Ruas Kanan persamaan Poisson.

Pada penelitian ini Algoritma Penyelesaian Masalah diimplementasikan pada beberapa bahasa pemrograman yaitu Fortran, Java dan MATLAB.

Diagam alir Metode Penyelesaian Masalah yang diangkat pada Penelitian ini dilukiskan pada Gambar 1.

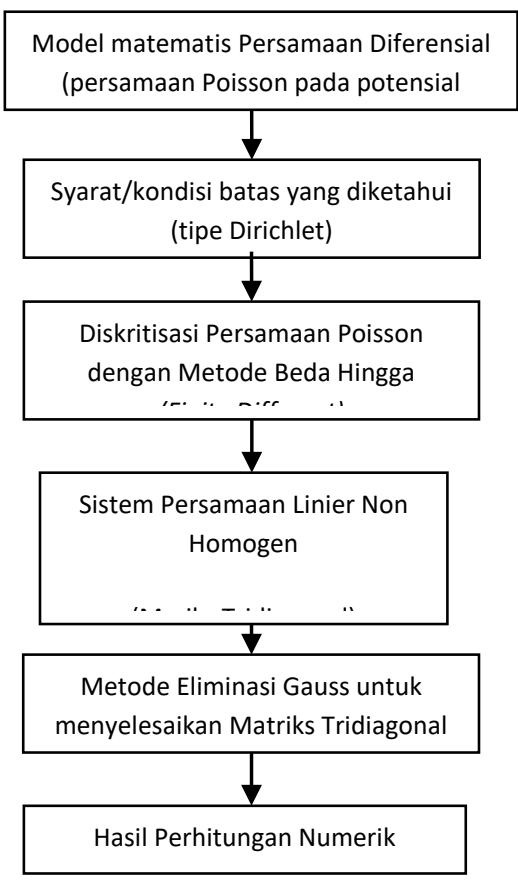

Gambar 1. Diagram alir metode penyelesaian masalah

\section{PEMBAHASAN}

Berikut adalah implementasi algoritma penyelesaian masalah dengan bahasa Fortran.

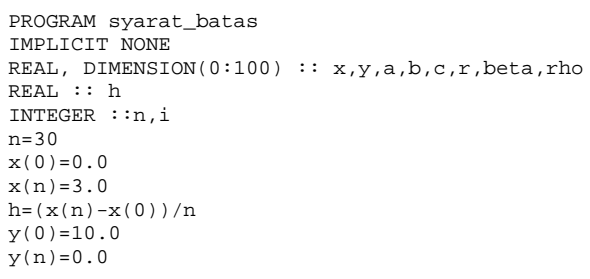

! Memasukkan unsur-unsur matrik a(i), b(i), c(i) dan $r(i)$ ! Khusus untuk $i=1$ dan $i=n-1$, unsur matriks $r(i)$ berbeda !dengan yang lain karena ada pengurangan dengan y॰ dan yn

DO $i=1,(n-1)$

$x(i)=x(\theta)+i * h$

$b(i)=-2.0$

IF (i . EQ. 1) THEN

ELSE $r(i)=f(x(i))^{*} h^{* *} 2-y(0)$

IF (i .EQ. $(n-1))$ THEN $r(i)=f(x(i)) * h^{* *} 2-y(n)$

ELSE

$$
\text { END IF }
$$




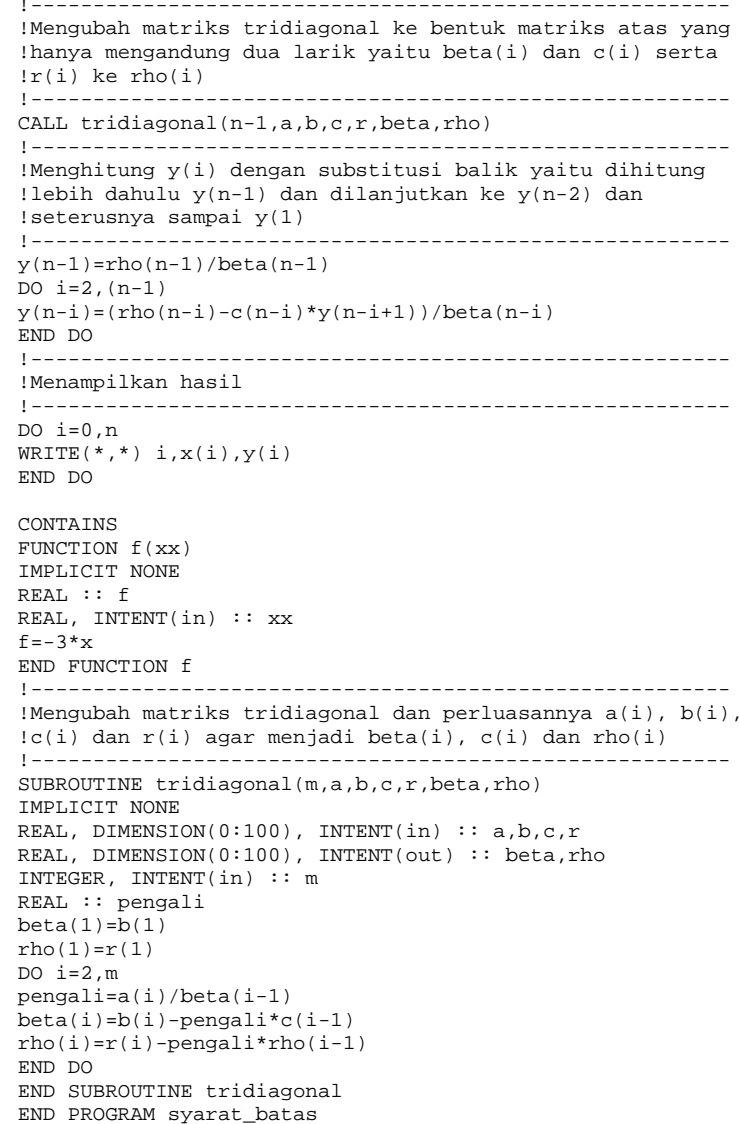

Dalam bahasa Java, algoritma penyelesaian masalah ditulis seperti berikut.

public class syaratBatas \{

public static void main(String args[]) \{

// DIFINISI VARIABEL DALAM ARRAY

double $x[]=$ new double [100]

double $y[]=$ new double [100]

double $a[]=$ new double [100]

double $b[]=$ new double $[100]$

double $c[]=$ new double [100]

double $r[]=$ new double [100]

double rho[]=new double[100]

double beta[]=new double [100]

double $h$, pengali;

int $\mathrm{N}, \mathrm{i}$;

// SYARAT BATAS

SYARAT

$\mathrm{N}=30 ;$
$\mathrm{x}[\mathrm{\Theta}]=0.0 ;$

$\mathrm{x}[\mathrm{\Theta}]=0.0 ;$
$\mathrm{x}[\mathrm{N}]=3.0 ;$

$\mathrm{h}=(\mathrm{x}[\mathrm{N}]-\mathrm{x}[\mathrm{O}]) / \mathrm{N}$

$y[O]=10.0$
$y=(\mathrm{X}]=0.0 \%$

$\mathrm{y}[\mathrm{O}]=10.0 ;$
$\mathrm{y}[\mathrm{N}]=0.0 ;$

* mengisi matrik tridiagonal dan vektor kolom ruas kanan

* mengisi matrik tridiagonal dan vektor kolom ruas kanan $(a, b, c, r) ; \quad$ Memasukkan unsur-unsur matrik a(i), b(i), $c(i)$ dan
$r(i) ; \quad$ Khusus untuk $i=1$ dan $i=n-1$, unsur matriks $r(i)$ berbeda dengan yang lain karena ada pengurangan dengan yo dan $\mathrm{yn}^{*} /$

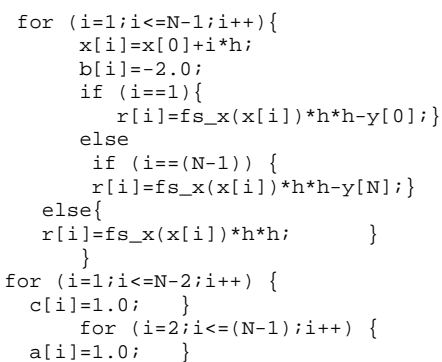

/* Mengubah matriks tridiagonal dan perluasannya $a(i), b(i)$, $c(i)$ dan $r(i)$ agar menjadi beta(i), $c(i)$ dan rho(i) */

beta $[1]=b[1]$

rho $[1]=r[1] ;$
for $(i=2 ; i<=(N-1) ; i++)\{$

pengali=a[i]/beta[i-1];

pengali=a[i]/beta $[i-1] ;$
beta $[i]=b[1]-$ pengali* $[i-1] ;$

beta[i] $=\mathrm{b}[1]-$ pengali*c $[i-1]$
rho $[i]=r[i]-$ pengali*rho $[i-1]$

?

\}/*Menghitung $y(i)$ dengan substitusi balik yaitu dihitung lebih dahulu y(n-1) dan dilanjutkan ke y(n-2) dan seterusnya sampai $\mathrm{y}(1)$ */

$y[\mathrm{~N}-1]=\mathrm{rho}[\mathrm{N}-1] /$ beta $[\mathrm{N}-1]$
for $(\mathrm{i}=2 ; \mathrm{i}<=(\mathrm{N}-1) ; \mathrm{i}++)\{$

$y[\mathrm{~N}-\mathrm{i}]=(\mathrm{rho}[\mathrm{N}-\mathrm{i}]-\mathrm{c}[\mathrm{N}-\mathrm{i}] * \mathrm{y}[\mathrm{N}-\mathrm{i}+1]) / \operatorname{beta}[\mathrm{N}-\mathrm{i}]$

// tampilkan hasil perhitungan lengkap beserta batas for $(i=0 ; i<=N ; i++)\{$

System. out . format ("\%०2d" + "\%10.4f" + "\%10.4f\%n", (i), x[i], $\mathrm{y}[\mathrm{i}]) ;)\}$

// DEFINISI FUNGSI

public static double fs_x(double $x)\{$

\}

return $-3^{*} x$;

Dengan MATLAB bentuk source code penyelesaian masalah adalah sebagai berikut.

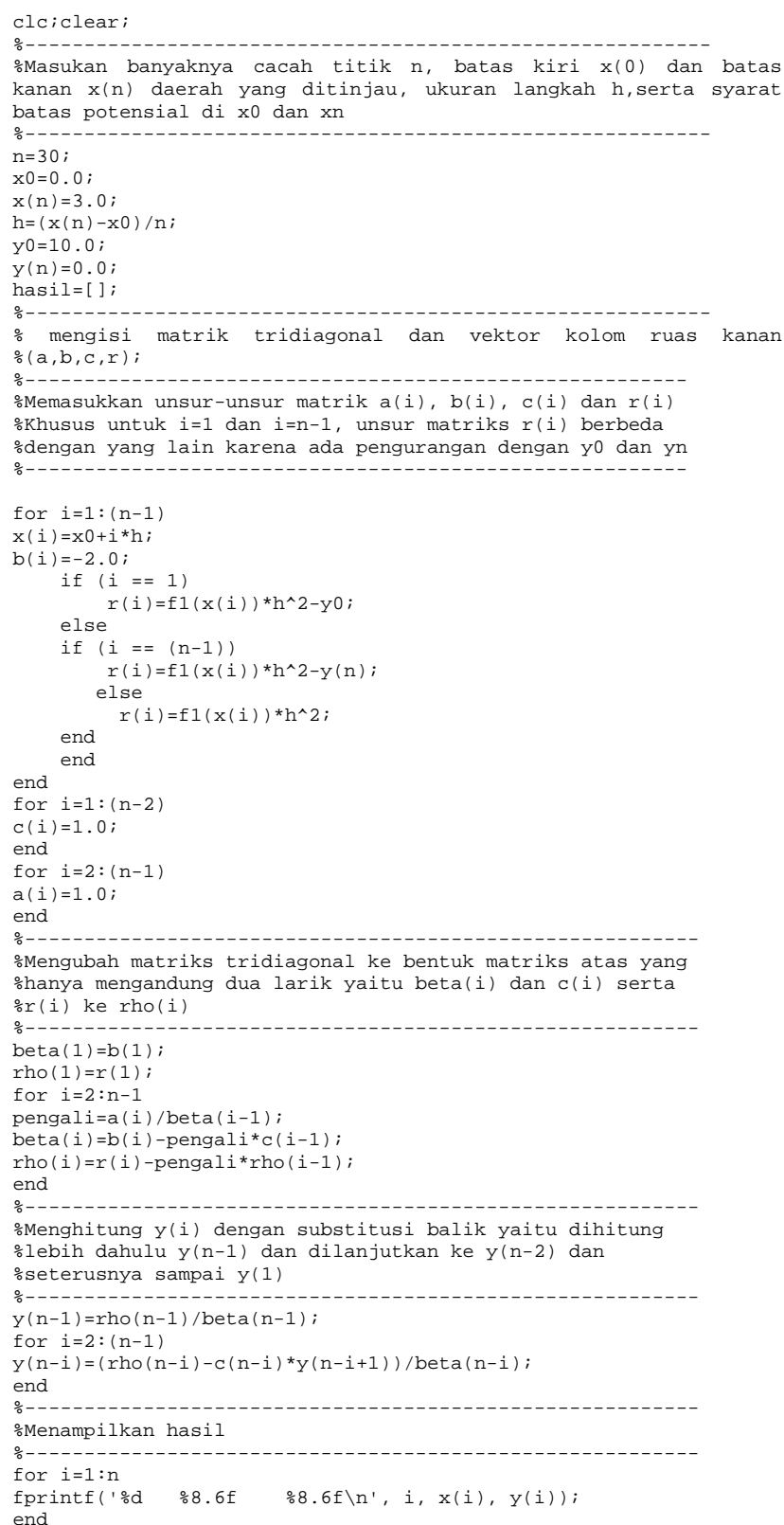

M-file untuk menyatakan fungsi ruas kanan peramaan ditulis terpisah di M-file bernama f1 . m seperti berikut

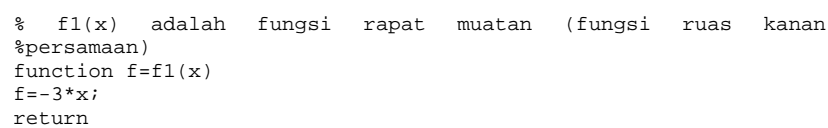

Hasil Running Fortran, Java dan MATLAB berturutturut ditunjukkan seperti Gambar 2, Gambar 3 dan Gambar 4. 


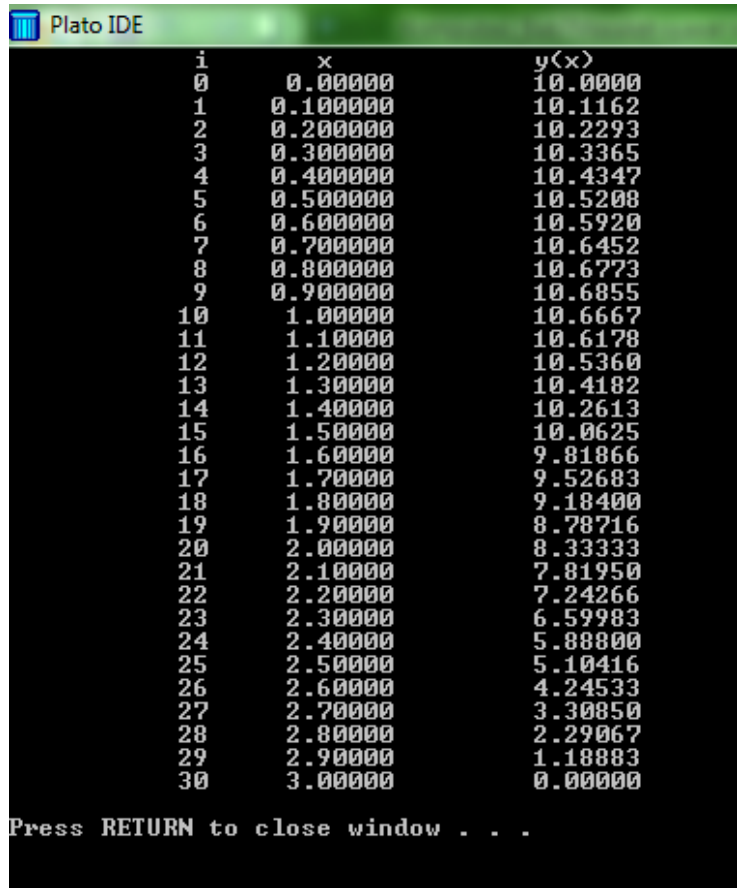

Gambar 2. Hasil Running program di bahasa Fortran

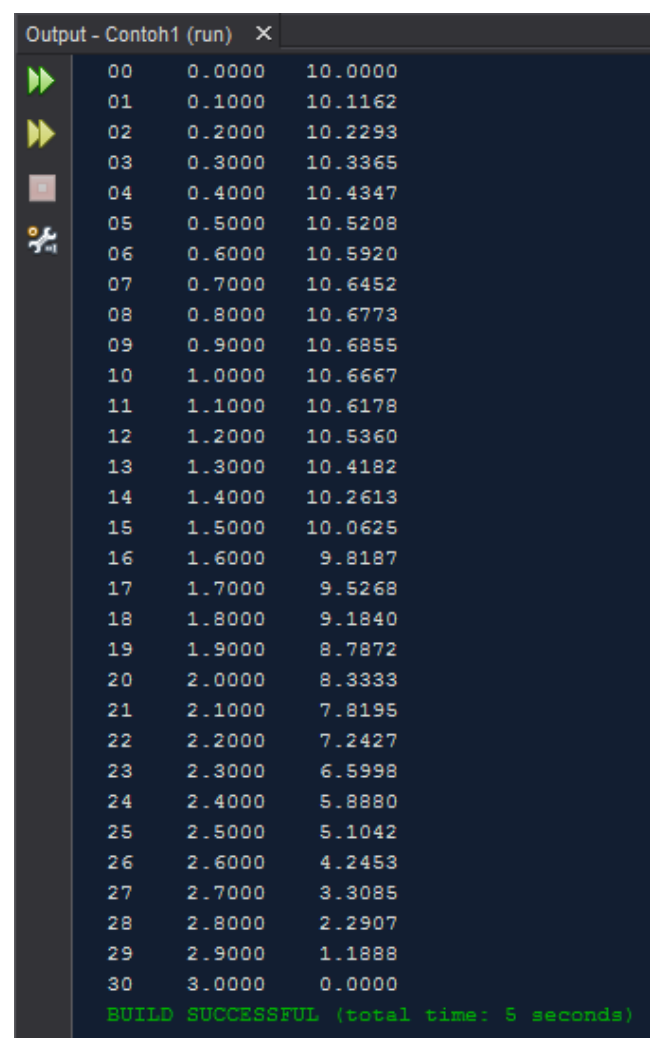

Gambar 3. Hasil Running program di bahasa Java

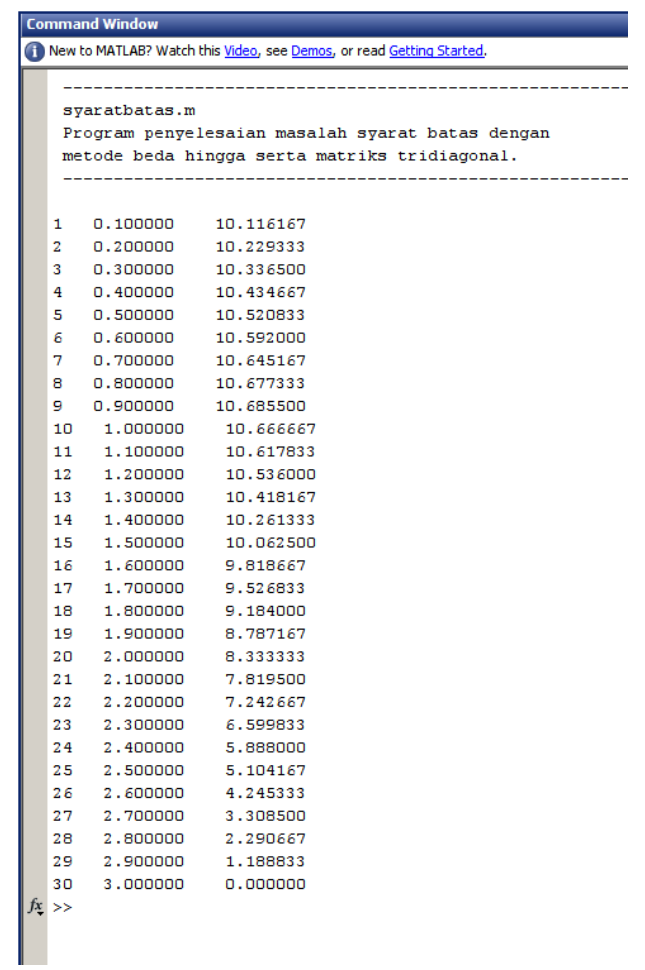

Gambar 4. Hasil Running program di MATLAB

Gambar 5 melukiskan grafik hasil perhitungan numerik nilai potensial listrik $\phi(x)$ terhadap jarak.

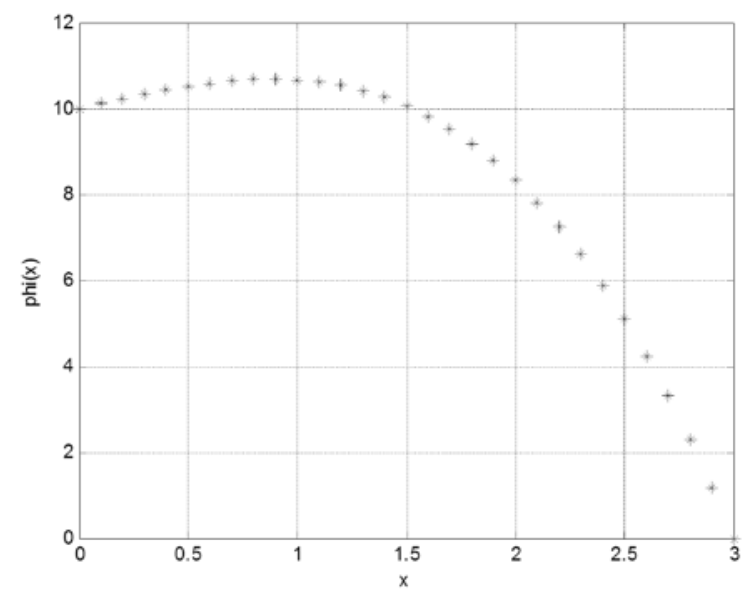

Gambar 5. Nilai potensial listrik terhadap jarak

\section{KESIMPULAN}

Dari hasil kajian numerik ini dapat disimpulkan bahwa metode beda hingga yang menghasilkan matriks tridiagonal yang diselesaikan dengan eliminasi Gauss dapat digunakan sebagai salah satu cara menyelesaikan persamaan diferensial biasa, orde dua, linier yang disertai dengan kondisi batas seperti kasus menghitung potensial elektrostatis yang berbentuk persamaan Poisson 1D. Algoritma penyelesaian masalah pada dapat 
diimplementasikan di beberapa bahasa pemrograman.

\section{DAFTAR PUSTAKA}

Koonin, S.E.,. 1990. Computational Physics Fortran Version. Addison-Wesley Pu. Co.Inc. New York.

Lam,C.Y.,1994. Applied Numerical Methods for Partial Differential Equations. Prentice Hall, London.

Rubin H.L., Manuel J.P., Cristian C.B., 2007. Computational Physics. Wiley VCH Verlag. Weinheim.

Sahid. 2005. Pengantar Komputasi Numerik dengan MATLAB. Penerbit Andi. Yogyakarta.

Suarga. 2007. Fisika Komputasi, Solusi Problema Fisika dengan MATLAB. Penerbit Andi. Yogyakarta.

Smith,G.D., 1969. Numerical Methods for Partial Differential Equations. Oxford University Press. London.

Yang W.Y, dkk. 2005. Apllied Numerical Methods using MATLAB. John Wiley \& Sons. New Jersey. 